\title{
Math Anxiety Trends: A Poor Math Attitude Can Be a Real Disability
}

\author{
Joseph M. Furner, Ph.D. \\ Department of Teaching and Learning, College of Education, Florida Atlantic University, Jupiter, FL, United \\ States \\ Email: jfurner@fau.edu
}

\begin{abstract}
Math anxiety remains a critical issue affecting student performance and confidence across grade levels throughout the world. This shares data on math anxiety trends and discusses how students' poor attitudes toward math can be the real disability for them in life. This paper provides much research and recommendations of best practices for teaching math and addressing such concerns in light of the reality of math anxiety existing in a world where we are preparing our young people for a STEM world. Research, best practices for teaching, strategies, and a survey are included.
\end{abstract}

Keywords: Math Anxiety, Attitudes, Disability, STEM, Best Practices

\section{Introduction}

\section{"Attitudes are the real disability." \\ -Henry Holden}

When I tell someone that I am a math teacher, usually he/she says, "I hated math" or "Math was my worst subject." Unfortunately, many people do not like math or have had bad experiences with taking the subject. Recently the quote above by Holden (Pierce, 2014) was spotted on a T-shirt at a gym and it hit home as to the fact that having a bad attitude or dislike toward math can really be a disability for one in their life. Negative attitudes toward mathematics and math anxiety are serious obstacles for students in all levels of schooling today (Furner, 2017; Geist, 2010). Yet only limited attention has been devoted to the antecedents of math anxiety, which may include social factors like exposure to teachers who themselves suffered with math anxiety (Maloney \& Beilock, 2012). This study looks at the math anxiety levels among students K-12 and shares a trend in math anxiety as students increase in grade level.

An elementary school principal from the school that this data in this paper is from told the author once that she always interviews all new students coming into the school and always asks students, "What is your favorite subject?" She said that most of the younger children always say to her, "math." The same school had decided to as part of their Southern Association of Colleges and Schools (SACS) accreditation as a K-12 international school (USA based curriculum) in Latin/South America to survey $25 \%$ of their students at each grade level (they have approximately 100 students per grade), Grades 1-12, and administered the Abbreviated Version of the Mathematics Anxiety Rating Scale(MARS) (Alexander and Martray, 1989) to see how their students feel about their math attitudes (See Figures 1 and 2). The results are somewhat inconclusive, but the graph shows primarily that as students increase in grade, their level of math anxiety increases for the most part (See Figure 1 and Table 1). This may not be a complete surprise and seems consistent with the Third International Mathematics and Science Study (TIMSS) math results in the USA, whereas students increase in grade, their level of math achievement drops significantly from elementary, to middle, then to high school (Schmidt, 1998). Today in an age of preparing our young people for fields in the areas of Science, Technology, Engineering, and Mathematics (STEM), it is critical young people have positive dispositions and attitudes toward mathematics. 


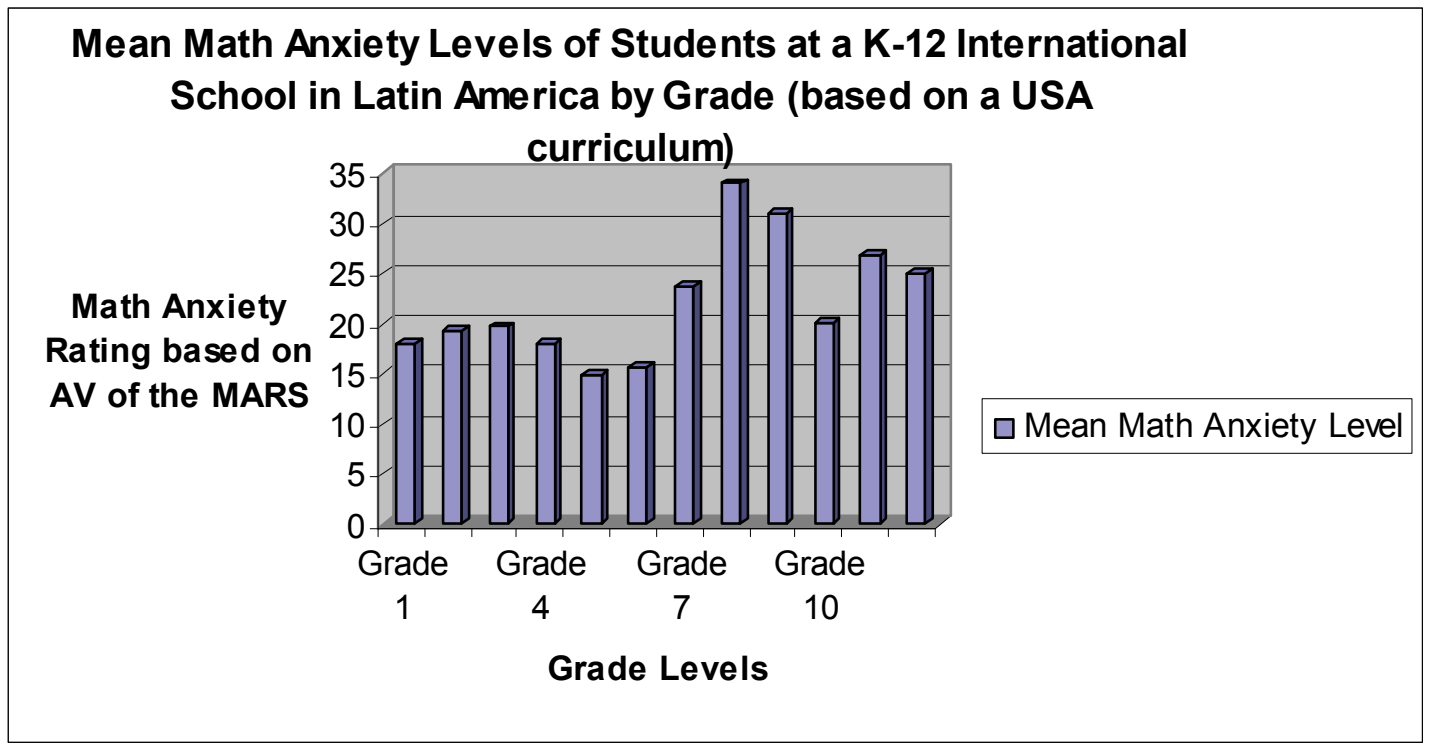

Figure 1. Mean math anxiety levels by grade

Table 1. Raw data of math anxiety levels by grade

\begin{tabular}{lc}
\hline Grade & Average of the MARS \\
\hline Grade 1 & 18 \\
Grade 2 & 19.3 \\
Grade 3 & 19.7 \\
Grade 4 & 18 \\
Grade 5 & 15 \\
Grade 6 & 15.7 \\
Grade 7 & 23.8 \\
Grade 8 & 34 \\
Grade 9 & 31 \\
Grade 10 & 20 \\
Grade 11 & 26.8 \\
Grade 12 & 25 \\
\hline
\end{tabular}

According to Reuters (2007) and the American Association for the Advancement of Science in San Francisco, math anxiety saps working memory to do mathematics. Often times, worrying about doing math takes up a large part of a student's working memory, which then spells disaster for the anxious student who is taking high-stakes tests. Today math teachers around the world almost have to take on the role of counselors in their classrooms to address the many students who dislike or are fearful of mathematics. Mathematics teachers are encouraged to work with school counselors and Exceptional Student Education (ESE) teachers in helping to address the many math anxious students in today's schools. Today math anxiety and dislike has become to epidemic levels in our schools as so many young people and adults have poor dispositions and bad past experiences with learning mathematics (Furner, 2017). Metje, Frank, \& Croft, (2007) believe that math anxiety is a worldwide phenomenon and that many people are not going into math fields like engineering and that more and more math instructors at the university level are not prepared to deal with the increased number of students who fear math to be able to teach and reach them during instruction, addressing math anxiety has become one of the largest challenges for a lecturer is supporting the students overcoming this fear of mathematics.

Today anyone may do an informal survey on the street and discover that most people will not report positive experiences, dispositions, or good attitudes toward math. Now in the STEM world we live in, we are all encouraged to be good at math and problem solving in our lives if we are going to be successful (Furner, 2017). Today we are living in a world in which our students will soon be competing 
with young people from all parts of the globe for jobs. It is imperative that our students develop positive dispositions toward mathematics and the sciences in an information age of which has become so technologically oriented. Young people today need to be well prepared in the areas of math, science, and technology for all career choices. Nurses, engineers, architects, lawyers, teachers, along with many other fields will continue to use more advanced forms of technology that require one to know more mathematics and problem solving to perform their jobs more effectively. Sequencing, ordering, patterning, logic, spatial sense, and problem solving are some of the truly basic skills that all careers require (NCTM, 2000). By the time our young people reach middle school, they have developed certain dispositions toward mathematics. Students' confidence and ability to do mathematics and apply these skills in many diverse settings is essential for success; therefore, our young people need to be well prepared to do the mathematics of the 21st century.

Steen (1999) found that "national and international studies show that most U.S. students leave high school with far below even minimum expectations for mathematical and quantitative literacy." Neunzert (2000) contends that we have to understand ourselves as MINT-professionals, where MINT is $\mathrm{M}=$ mathematics, $\mathrm{I}=$ informatics, $\mathrm{N}=$ natural sciences, $\mathrm{T}=$ technology. Neunzert (2000) believes that mathematics is critical for people living in the 21st Century for them to be successful. Neunzert feels as educators we need to encourage our students in all countries to study more mathematics and to see it as a tool for success in life.

\section{Math Anxiety}

What is math anxiety? Well, to put it simply, it is anxiety when confronted with math, especially about one's own performance in solving math problems. It can range from slight nervousness to all-out panic. This anxiety makes it more difficult for students to focus in class, learn math, and solve math problems. Frequently students would rather give up than have to face their fears. This means that they never get better at math and can therefore never overcome their anxiety. If this math anxiety is not defeated, the student may suffer from this anxiety for their entire life, even beyond their time in school. Math anxiety is a well-documented phenomenon that has affected our society for over sixty years, and not enough is being done to address it in our classrooms or in the way we teach math (Furner, 2017: Beilock \& Willingham, 2014; Boaler, 2008; Dowker, Sarkar, \& Looi, 2016; Geist, 2010; Metje, Frank, \& Croft, 2007). Negative attitudes toward mathematics and math anxiety are serious obstacles for students in all levels of schooling today (Geist, 2010). Beilock and Willingham (2014) state that "Because math anxiety is widespread and tied to poor math skills, we must understand what we can do to alleviate it" (p. 29).

What Causes Math Anxiety? Math anxiety is caused by a combination of external and internal factors; however, we cannot change internal factors within the student, so as teachers it makes more sense to focus on what we can control (Chernoff \& Stone, 2014). Studies show that math anxiety is caused primarily by the way the student learns math: the type of authority the teacher uses, an emphasis on right answers and fear of getting wrong answers, requirements that the student respond with an answer sooner than he or she might be ready, and exposure to the rest of the class and their potential condemnation of a student who responds poorly, in short the traditional way of teaching math (Chernoff \& Stone, 2014, Finlayson, 2014). Traditional teaching emphasizes:

$>$ "Basic skills

$>$ Strict adherence to fixed curriculum

$>$ Textbooks and workbooks

$>$ Instructor gives/students receive

$>$ Instructor assumes directive, authoritative role

$>$ Assessment via testing/correct answers

$>$ Knowledge is inert

> Students work individually." (Finlayson, 2014)

Unfortunately, these methods can cause and increase math anxiety in the classroom (Finlayson, 2014). Math anxiety can also be transmitted and learned from others, usually from parent to child or teacher to student, but occasionally student-to-student. If someone teaching math, whether to their own child or to a class, experiences math anxiety, they are more likely to rush through things in order to "get it over with". They would not be sure of their methods, so they would focus more on the correct answers. Like 
the student with math anxiety, they are also likely to become exasperated and give up rather than continue to get. When this is done it teaches the student that math is something to be afraid of and that, if they are not good at it, their parent or teacher will become angry with them and potentially leave (Furner, 2017). They also learn in class that, if their peers see that they are bad at math, they will be ridiculed publicly. Embarrassment is a very big deal for children, especially in the middle and high school grades.

Another problem for those who suffer from math anxiety is the nature of anxiety itself. According to Rubinstein et al (2015), anxious individuals tend to focus on negative stimuli more than positive stimuli, essentially making themselves more anxious. The same thing is true of individuals with math anxiety; the only difference is that for people with math anxiety, math is negative stimuli (Rubinstein et al, 2015). This suggests that math anxiety could be handled through therapies designed to lessen anxiety, such as cognitive behavioral therapy and exposure therapy (exposing a person little by little to the thing that they are afraid of) (Rubinstein et al, 2015). While this is not something that a teacher could do with a full class to manage, it is something that tutors could be trained to help with; naturally, a licensed therapist would be the best option, but not all therapists are trained to help students with math. A combination of the two fields would be optimal.

Math anxiety remains a perplexing, persistent, and only partially understood problem from which many people suffer, NCTM (1991, p. 6) says, "Classrooms should be mathematics communities that thrive on conjecturing, inventing, and problem solving, and that build mathematical confidence. Unfortunately, currently, many kids and adults do not feel confident in their ability to do math. Mathematics anxiety in students has become a concern for our high-tech world. Is it possible that only about seven percent of Americans have positive experiences with math classes from kindergarten through college study (Jackson, C. D. \& Leffingwell, 1999)? Burns (1998) in her book Math: Facing an American Phobia tackles an interesting subject and has found that two-thirds of American adults fear and loathe math. Whether it is $93 \%$ or two-thirds of Americans experiencing negative math experiences it is clear that there is a problem and we need to do something about it as educators. If math anxiety is such a problem, one has to wonder why is not as much being done about it in our schools today?

Evidence of students' poor attitudes and high levels of anxiety toward math is abundant today. In the midst of a technological era, declining mathematics (math) scores on the Scholastic Aptitude Test (SAT) have been widely publicized. Some reports have shown that American students rank last when compared with students from all other industrialized countries on 19 different assessments. The TIMSS study has shown a trend in U. S. students' math scores as they decline as students increase in age group from grade four to grade twelve (Schmidt, 1998). Math educators need to ask ourselves what is happening to today's youth that so many of them lose interest in math and lack the self-assurance to do and take more math classes in our schools today?

\section{How Do We Repair Math Anxiety Concerns in Our Schools?}

To put it simply: better teaching. Finlayson suggests the constructivist style of teaching which emphasizes these ideas:

$>$ Begin with the whole - expanding to parts in learning process

$>$ Pursuit of student questions/interests

$>$ Use primary sources/manipulative materials

$>$ Learning is interaction - building on what students already know, constructivism

$>$ Instructor interacts/negotiates with students

$>$ Assessment via student work, observations, points of view, and tests. Process is as important as product

$>$ Knowledge is dynamic/change with experiences

$>$ Students should work in groups (2014)

This style of teaching is very different from the traditional style which can cause and increase math anxiety. The constructivist style is much less intimidating and does not emphasize timed assessments or correct answers; instead, it focuses on the process of doing mathematics. Students are also likely to feel more engaged in class due to the more participatory style of teaching, making them want to work harder, instead of "getting it over with" heedless of how this affects their performance. 
However, frequently the problems in the classroom that cause math anxiety are due to a teacher with math anxiety (Chernoff \& Stone, 2014). These teachers choose the easiest ways of teaching (rote memorization of formulas, practice using one method to get one right answer, timed tests, etc.) in order to minimize their own math anxiety, not realizing that they are passing their own anxiety onto their students (Chernoff \& Stone, 2014). Therefore, we must first remove math anxiety from teachers, so they may teach their students not to experience math anxiety. Math is not inherently frightening, but that is the message that is modeled and expressed to many children, even from their parents and teachers.

As mentioned previously, math anxiety is a form of anxiety and therefore treatable through the same types of therapy we use to treat general anxiety and phobias (Rubinstein et al, 2015). This may prove especially helpful for adults with math anxiety, especially teachers; by working to handle their own math anxiety, adults would be able to prevent transmission of their anxiety to their children or students (Chernoff \& Stone, 2014).

\section{Discussing the Data from the K-12 School's Math Anxiety Levels in This Study}

The major trend from this data shows a notable upward trend in math anxiety in students as students increase in grade level (See Figures 1 and 2). As students take more math classes and are exposed to more math teaching, unfortunately their level of math anxiety increased in this data set of a K-12 International School in South America with a US-based curriculum. In discussions with the administrators and teachers, little is often done year to year with students as they pass from grade to grade in respect to addressing a students' math anxiety. This math anxiety can fester and continue to pass on and increase as students continue through their studies. The author of this paper worked with this school for two years during this data collection in the school as part of the SACS accreditation. He also worked as the 9th Grade Geometry teacher for the first year prior to the data collection year and has extensive expertise in math anxiety research and implemented extensive math anxiety reduction and prevention techniques. The author employed these techniques with the 9th Grade mathematics students the year prior to the data collection. It is visible to see that the 10th Grade Students had reduced levels of math anxiety, likely due to the preventative and reductive math anxiety techniques used. Preventative strategies: like using "Best Practice" in mathematics include using: manipulatives, cooperative groups, discussion of math, questioning and making conjectures, justification of thinking, writing about math in math journals, using a problem-solving approach to instruction, content integration, using technology Geometer's Sketchpad, assessment as an integral part of instruction, such as homework quizzes and math portfolios. Along with math anxiety reductive strategies which include using: psychological techniques such as anxiety management, desensitization, counseling, support groups, bibliotherapy, and classroom discussions of how students feel about math and what they are learning. These insights can better help to understand why the 10th Grade class had significantly lower math anxiety than the other middle school and high school grades. Students in elementary school often start out with little math anxiety, but this anxiety can increase as students go from grade to grade in their learning process. It is critical in an age of STEM (Science, Technology, Engineering, and Mathematics) that schools and teachers work to correct this trend of increase in math anxiety age students go from Grades K-12. More schools need to include affective aspects into their improvement plans, like checking for math anxiety, and then compare such data to their students' achievement levels. Unfortunately, like TIMSS showed for US schools, the trend of math achievement went down as students increased in grade like this study shows with math anxiety and it is likely correlations exist with how students feel about mathematics and how they perform. School leaders need to start looking at both affective and cognitive aspects of learning to see the relationships and to better address achievement and performance of their students in mathematics and likely all subjects.

\section{Teachers, Counselors, and ESE Teachers Working Together to Improve Math Scores}

To address the issue of math anxiety, classroom teachers need to team up with school counselors, ESE 
teachers, and professional development experts in teaching mathematics and make this all a part of their improvement plan, to assess attitudes toward math to then work toward improving math achievement. Teachers need to be sensitive to students' needs, feelings, and experiences with mathematics. Brigman \& Campbell (2003) and Parker (1997) have found based on their research that when school counselors team up with classroom teachers they can have a profound effect on student achievement scores. A counselors' psychological expertise can serve as a real asset to classroom teachers and students who struggle with a fear of mathematics or poor past math instruction experiences. As educators, we need to remember that not all students are alike, yet all students deserve equal opportunities in the mathematics classroom (NCTM, 2000). A math teachers' job is not only to teach the subject area. One of NCTM's goals for all learners was that as math teachers, we should help students become confident in their ability to do mathematics (NCTM 1989). NCTM $(1989,2000)$ contends that students should be exposed to numerous and varied interrelated experiences that encourage them to value math, to develop mathematical habits of the mind, they should understand the role of math in human affairs: they should be encouraged to guess, read, write, make conjectures and make errors so that they can gain confidence to solve complex problems. With this in mind, it is clear then that math teachers are not only instructional leaders, they are also counselors and confidence builders for their clients, their students.

Math anxiety may be defined as an inconceivable dread of mathematics that can interfere with working with numbers and solving word problems within a variety of everyday world and academic situations. NCTM (1989 \& 1995) recognizes math anxiety as a problem and has specifically included in its assessment practices as a teacher's job to assess for their students' mathematical dispositions as NCTM Standard \#10 (NCTM, 1989) (See Appendix A)

Today there are many things teachers and schools can do to help prevent math anxiety from occurring in our students. It really is a complicated matter and may involve what happens to students in and outside of the classroom. Both parents and teachers can play vital roles in helping to develop positive dispositions toward math in students. It is important that teachers check for these positive attitudes and dispositions toward mathematics at an early age. Often students can develop such anxieties toward math very early on in their math classrooms due to poor teaching, drill and practice, strained testing situations, parental and teacher insecurities about their own math abilities, etc. The elementary and middle school years are critical to developing positive perceptions toward mathematics in children. The NCTM $(2000,1995$, \& 1989) has made recommendations for preventing and reducing math anxiety (See Appendix A).

Reducing math anxiety is much different from preventing math anxiety. Teachers need to work with school counselors and to act as psychologist or counselors themselves to help lower or overcome such anxiety toward math in their students. It is critical that math teachers team up with school counselors to address reducing math anxiety in their students. Researchers in math anxiety propose systematic desensitization (Arem, 2003;Furner, 1996; Schneider \& Nevid, 1993; Hembree, 1990; Trent, 1985; Tobias, 1993; Olson \& Gillingham, 1980) as one of the most effective approaches for helping people reduce their math anxiety. Systematic desensitization in the context of math anxiety may be defined as a gradual exposure to the mathematical concepts that are causing students to become distressed and teaching them how to cope with that fear they are dealing with. Each time students are exposed to the math they fear, they should improve in their techniques in coping with their anxious feelings. Being able to talk about their history with math and releasing their anger, hatred and fear of the subject may be therapeutic in nature and then eventually students can work toward, come to terms with this anxiety, and overcome it. Through these types of counseling approaches, students will be able to come to understand that their anxiety was a learned behavior, which they were not born with these feelings toward math, and they can be taught to overcome them by consistently implementing their self-monitoring strategies to become less anxious.

How is math anxiety reduced? Teachers must help students understand how their math anxiety was created (See Appendix A) and work toward overcoming this fear while developing confidence. As Reuters (2007) and the American Association for the Advancement of Science in San Francisco reported, a relationship does exist between math anxiety levels and math achievement levels. Teachers can work with school counselors and be counselors themselves to ease such anxiety and work toward helping the students gain more confidence in doing math so that math achievement levels improve. In the case of the school mentioned here that is also assess math attitudes using the abbreviated Version of the MARS, 
they are using this information to work more closely with students to then help them overcome their math anxiety so that the school will hope to see high math achievement levels in the years to come.

\section{Summary}

Math anxiety is a major problem in today's world. As the old adage says, "attitude is everything," when students have bad attitudes toward mathematics, it can affect their lives forever. As adults, we need to be aware of our own anxiety in order to prevent it from being transmitted to our children and students; for those who are unduly impacted by math anxiety or for those who are more likely to transmit this anxiety to children, it may be helpful to receive assistance from a therapist. The data presented in this paper show little math anxiety with the early grades and increasing as students go up in grade. As math teachers, we need to make our classrooms a safe haven for students with math anxiety by altering our teaching styles; this will help all students, not just those with math anxiety. In order to fix this problem, we need to go straight to the source, even if that source is in our own anxieties. Only then can we prevent future generations from becoming part of the pandemic of math anxiety. Today math teachers really must take on the role of counselors to address their students bad attitudes toward mathematics; while addressing both preventative and math anxiety reduction strategies with their students to improve math attitudes (Furner, 2017).

Math teachers should be teaming up with school counselors and ESE teachers to employ the many suggestions and recommendations mentioned in this article in their classrooms/schools to help prevent and reduce math anxiety. Today, teachers need to put on their educational psychologists hats on in their classrooms to help address the issue of math anxiety. Teachers may also want to work with school counselors as well as encourage their schools to have family math nights where parents come with children and together they can "do math" and see its importance and value in life. As a society, we must work together to extinguish the discomfort that our youngsters are having toward mathematics, especially as students increase in age. It is important that all students feel confident in their ability to do mathematics in an age that relies so heavily on problem solving, technology, science, and mathematics. Today's educators must make the difference in our children's attitudes toward math. Math teachers working with school counselors and ESE teachers can strive toward creating mathematically literate and confident young people for the new millennium. The data in this study shows an upward trend in higher math anxiety levels as students increase in grade level. It is evident teachers need to do more starting in the early grades and each grade to use best practices for teaching math and also use math anxiety reduction strategies to work on reducing math anxiety as students increase go up in grade. It would be nice to hear more young people and adults when asked how they feel about math say, "Math was my favorite subject" or "I am great at math!" not "I hate it" which seems to be more often heard by adults in the 21st Century. We need to flat line this trend, not allowing it to create an escalating a bar graph of increases as students increase in grade level. As math educators, we need to correct these poor attitudes toward mathematics so that it is not a disability for our students as they go about their lives.

\section{References}

1. Alexander, L., \& Martray, C. (1989). The Development of an Abbreviated Version of the Mathematics Anxiety Rating Scale.

2. Measurement and Evaluation in Counseling and Development, 22, 143-150.

3. Arem, C. A. (2003). Conquering Math Anxiety: A Self-Help Workbook (2 ${ }^{\text {nd }}$ Ed.). Pacific Grove CA: Brooks/Cole-Thomson Learning.

4. Beilock, S. L., \& Willingham, D. T. (2014). Math anxiety: Can teachers help students reduce it? American Educator, 38(2), 28-32.

5. Boaler, J. (2008). What's math got to do with it? Helping children learn to love their leastfavorite subject--and why it's important for America. New York, NY: Penguin Group (USA) Inc.

6. Brigman, G. \& Campbell, C. (2003). Helping student improve academic achievement and school success behavior. Professional School Counseling, 7(2), 91-98.

7. Burns, M. (1998). Math: Facing an American Phobia. Sausalito, CA: Math Solutions Publications. 
8. Chernoff, E., \& Stone, M. (2014). An Examination of Math Anxiety Research. OAME/AOEMGazette, 29-31.

9. Dowker, A., Sarkar, A., \& Looi, C. Y. (2016). Mathematics Anxiety: What Have We Learned in60 Years? Frontiers in Psychology, 7, 508. http://doi.org/10.3389/fpsyg.2016.00508

10. Finlayson, M. (2014). Addressing math anxiety in the classroom. Improving Schools, 17(1), 99-115. doi:10.1177/1365480214521457

11. Furner, J. M. (2017). Teachers and counselors: Building math confidence in schools. European Journal of STEM Education, 2(2), 1-10. https://doi.org/10.20897/ejsteme.201703

12. Furner, J. M. (1996). Mathematics teachers' beliefs about using the National Council of Teachers of Mathematics Standards and the relationship of these beliefs to students' anxiety toward mathematics. Unpublished doctoral dissertation. University of Alabama.

13. Geist, E. (2010). The anti-anxiety curriculum: Combating math anxiety in the classroom, Journal of Instructional Psychology, 37(1), p24-31

14. Hembree, R. (1990). The Nature, Effects, And Relief of Mathematics Anxiety. Journal for Research in Mathematics Education, 21, 33-46.

15. Jackson, C. D., \& Leffingwell, R. J (1999). The Role of Instructor in Creating Math Anxiety in Students from Kindergarten Through College. Mathematics Teacher, 92(7), 583-586.

16. Metje, N., Frank, H. L., \& Croft, P. (2007). Can't do maths - understanding students' maths anxiety. Teaching Mathematics and its Applications: An International Journal of the IMA, 26(2), 79-88.

17. National Council of Teachers of Mathematics. (1989). Curriculum and Evaluation Standards for School Mathematics. Reston, VA: Author.

18. National Council of Teachers of Mathematics. (1991). Professional Standards for Teaching Mathematics. Reston, VA: Author.

19. National Council of Teachers of Mathematics. (1995). Mathematics Anxiety [Supplemental Brochure]. Reston, VA: Author.

20. National Council of Teachers ff Mathematics. (2000). Principles and Standards for School Mathematics. NCTM: Reston, VA

21. Neunzert, H. (2000). Will Mathematics and The Mathematicians Be Able to Contribute Essentially in Shaping the Future? Paper Presentation at The 3ECM Conference Round Table Discussion On Shaping The 21st Century, Barcelona, Spain, July 11-14, 2000.

22. Olson, A. T. \& Gillingham, D. E. (1980). Systematic desensitization of mathematics anxiety among preservice elementary teachers. Alberta Journal of Educational Research, 26(2), 120 - 127.

23. Parker, S. L. B. (1997). Overcoming Math Anxiety: Formerly Math-Anxious Adults Share Their Solutions. Educational Specialist Thesis at the University of Georgia.

24. Pierce, M. (2014). We Survived. Retrieved October 10, 2018 at: http://wesurvive.org/attitudes-are-the-realdisability/

25. Reuters. (2007). Researchers: Math Anxiety Saps Working Memory Needed to Do Math. POSTED: 1:14 P.M. EST, Retrieved at Http://Www.Cnn.Com/Interactive on February 20, 2007.

26. Rubinsten, O., Eidlin, H., Wohl, H., \& Akibli, O. (2015). Attentional bias in math anxiety. Frontiers in Psychology, 6. doi:10.3389/fpsyg.2015.01539

27. Schmidt, W. H. (1998). Changing Mathematics in the U.S.: Policy Implications from the Third International Mathematics and Science Study. Presentation at the $76^{\text {th }}$ Annual Meeting of the National Council of Teachers Of Mathematics, Washington, D.C., April 3, 1998.

28. Schneider, W. J. \& Nevid, J. S. (1993). Overcoming Math Anxiety: A Comparison of Stress Inoculation Training and Systematic Desensitization. Journal of College Student Development, 3(4), 283 - 288.

29. Steen, L.A. (1999). Numeracy: The New Literacy for A Data-Drenched Society. Educational Leadership, October, 8-13

30. Tobias, S. (1993). Overcoming Math Anxiety Revised and Expanded. New York: Norton.

31. Trent, R. M. (1985). Hypnotherapeutic Restructuring and Systematic Desensitization as Treatment for Mathematics Anxiety. Paper Presented at The Annual Convention of the Southwestern Psychological Association, Austin, Texas. 


\section{Appendix A}

Standards and Strategies to Address Math Anxiety including the Mathitudes Survey

Name

Grade

Math Class

Age

Career or Career Interest

\section{Mathitude Survey}

1. When I hear the word math I.......

2. My favorite thing in math is......

3. My least favorite thing in math is.......

4. If I could ask for one thing in math it would be.

5. My favorite teacher for math is because

6. If math were a color it would be.....

7. If math were an animal it would be.....

8. My favorite subject is because

9. Math stresses me out: True or False Explain if you can.

10. I am a good math problem-solver: True or False Explain if you can 
Mathematics teachers need to be counselors too...

What NCTM says about Mathematics Anxiety and Dispositions Toward Mathematics

\section{Standard 10: Mathematical Disposition (NCTM 1989)}

As mathematics teachers it is our job to assess students' mathematical disposition regarding: -confidence in using math to solve problems, communicate ideas, and reason;

-flexibility in exploring mathematical idea and trying a variety of methods when solving;

-willingness to persevere in mathematical tasks;

-interests, curiosity, and inventiveness in doing math;

-ability to reflect and monitor their own thinking and performance while doing math;

-value and appreciate math for its real-life application, connections to other disciplines and cultures and as a tool and language.

\section{A Synthesis on How to Reduce Math Anxiety}

1. Psychological Techniques like anxiety management, desensitization, counseling, support groups, bibliotherapy, and classroom discussions.

2. Once a student feels less fearful about math he/she may build their confidence by taking more mathematics classes.

3. Most research shows that until a person with math anxiety has confronted this anxiety by some form of discussion/counseling no "best practices" in math will help to overcome this fear.

\section{A Synthesis on How to Prevent Math Anxiety}

1. Using "Best Practice" in mathematics such as: manipulatives, cooperative groups, discussion of math, questioning and making conjectures, justification of thinking, writing about math, problem-solving approach to instruction, content integration, technology, assessment as an integral part of instruction, etc.

2. Incorporating the NCTM Standards and your State Standards into curriculum and instruction.

3. Discussing feelings, attitudes, and appreciation for mathematics with students regularly 


\section{Author Bio}

Joseph M. Furner, Ph.D. is a Professor of Mathematics Education in the Department of Teaching and Learning at Florida Atlantic University in Jupiter, Florida. He received his Bachelor's degree in Education from the State University of New York at Oneonta and his Masters and Ph.D. in Curriculum and Instruction and Mathematics Education from the University of Alabama. His scholarly research relates to math anxiety, the implementation of the national and state standards, English language issues as they relate to math instruction, the use of technology in mathematics instruction, math manipulatives, family math, and children's literature in the teaching of mathematics. Dr. Furner is the founding editor of Mathitudes Online at:http://www.coe.fau.edu/centersandprograms/mathitudes/ He is the author of more than 80 papers. Dr. Furner has worked as an educator in New York, Florida, Mexico, and Colombia. He is concerned with peace on earth and humans doing more to unite, live in Spirit, and to care for our Mother Earth and each other. He is the author of Living Well: Caring Enough to Do What's Right. Dr. Furner currently lives with his family in Palm Beach, Florida. He enjoys his job, family, civic and church involvement and the beach. Please feel free to write to him at: jfurner@fau.edu. 